\title{
Fuentes documentales para crear confianza entre los usuarios digitales: propuestas desde los medios
}

Documentary sources to create trust among digital users: Proposals from media

\author{
Juan Carlos Marcos Recio \\ Universidad Complutense de Madrid, Madrid, España \\ Contacto: jmarcos@ucm.es \\ https://orcid.org/0000-0003-0890-1092
}

\begin{abstract}
Resumen
Los medios de comunicación han tardado más de dos siglos en lograr su reputación. Como por arte de magia ha desaparecido de la esfera mediática y los editores no encuentran una solución. ¿Culpables? Los propios medios que no supieron adaptarse a los nuevos entornos, las redes sociales que pasaron sin compasión por encima como un rodillo y los usuarios, lectores, oyentes, etc., que apostaron por la rapidez y sencillez de la información que les ofrecían las redes sociales. Y en esto llegó 2016. El año en que la comunicación política cambió el valor de la información y su relación con los medios, a partir de las propuestas del presidente Donald Trump. Desde entonces, un aluvión de informaciones falsas, producidas ad hoc por "mercenarios" del contenido, amplificadas en las redes sociales y aireadas a través de los medios impresos, han supuesto un nuevo orden en la comunicación. Este artículo analiza la situación actual con referencia a las Fake News y a la sociedad de la posverdad, en la que los medios están adaptándose y utilizando la tecnología para reorganizar la información. Se hace un seguimiento a diferentes organismos e instituciones que están mostrando resultados propicios para evitar la desinformación y las malas praxis. Finalmente, se ofrece desde las fuentes de información herramientas y recomendaciones para que los periodistas establezcan un orden de prioridades y se ajusten a los datos para crear una información acorde con la verdad y la justicia social.
\end{abstract}

Palabras clave: Fuentes de información; Usuarios digitales; Confianza; Fake News; Posverdad.

\begin{abstract}
The media have taken more than two centuries to achieve their reputation. As if by magic it has disappeared from the media sphere and the editors do not find a solution. Guilty? The media itself that did not know how to adapt to the new environments, the social networks that passed without compassion like a roller and, the users, readers, listeners, etc., who bet on the speed and simplicity of the information offered by the social
\end{abstract}


networks. And this was 2016. The year in which political communication changed the value of information and its relationship with the media, based on the proposals of President Donald Trump. Since then, a flood of false information, produced ah doc by "mercenaries" content, amplified in social networks and aired through the print media, have brought a new order in communication. This article analyzes the current situation with reference to the Fake News and the post-truth society, in which the media is adapting and using technology to reorganize information. A followup is made to different organizations and institutions that are showing auspicious results to avoid misinformation and bad practices. Finally, from sources of information, tools and recommendations are offered so that journalists establish an order of priorities and adjust to the data to create an information in accordance with truth and social justice.

Keywords: Information sources; Digital users; Trust; Fake News; Posttruth.

Recibido: 30.09.18 Aceptado: 02.02.19

\section{Introducción}

La terca realidad de la información ha cambiado incluso a más velocidad que la tecnología, de la que se sirve. Los procesos técnicos se han simplificado, la forma de producir contenidos también y la manera en que llegan es casi instantánea. Así, los periodistas no son solo espectadores observando una avalancha de desinformación. Son partes fundamentales en un proceso en el que perdieron el control. Antes eran indispensables para los políticos, actores, empresarios, etc., ahora ya no lo son tanto y su influencia cada día mengua. En todo caso, siguen siendo proactivos para mejorar la producción de contenidos cada día.

El periodismo ha vivido siempre atento a los cambios. Muchas veces tecnológicos y pocos con respecto al contenido, la manera de contar o la presentación de las noticias. Durante años se ha ido adaptando a la sociedad sin apenas tener problemas. Los lectores, oyentes, usuarios de los medios se conformaban con lo que aportaban cada día. No hacía falta más que saber lo que acontecía en una comunidad y algunas noticias en la distancia. Pero el mundo se hizo global y los medios tuvieron que correr para dar servicio a esa mundialización. En dicho cambio, el periodista perdió parte del control que fue cediendo al lector, quien ahora toma decisiones sobre lo que quiere o no quiere leer. 
Esa transformación es de tal magnitud que tras más de dos décadas de cambios, no se sabe exactamente el lugar que ocuparán los medios en un futuro próximo. ¿Se cansarán los usuarios de las redes sociales y regresaran a los medios tradicionales? ¿Serán necesarios nuevamente ante las imposiciones políticas, empresariales, religiosas? ¿Tendrán que seguir defendiendo situaciones que nadie más cuenta? Las respuestas no parecen sencillas, pero Posetti y Matthews (2018) avanzan algunas en una corta guía sobre las Fake News y la desinformación:

\begin{abstract}
Ahora habitamos un mundo con propaganda computacional, redes de títeres y marionetas patrocinadas por el estado, trolls armados y tecnología que puede imitar sitios web de noticias legítimos y manipular audio y video a la perfección para crear representaciones sintéticas de cualquier cantidad de fuentes. En este entorno, donde la confianza se polariza sobre qué "noticias" se alinean con sus puntos de vista, muchos consumidores de noticias se sienten con derecho a elegir o crear sus propios "hechos".
\end{abstract}

Y esa no es la solución. Porque las noticias son fruto de la creación de un periodista que maneja fuentes, que usa datos y que trata de ser objetivo al máximo.

Este artículo es fruto de un análisis y seguimiento a algunos de los principales medios de comunicación de Estados Unidos, Francia, Inglaterra y España, durante casi un año (2018). También se hizo un seguimiento a Lab's de información, instituciones educativas que trabajan la comunicación, redes sociales y expertos periodistas que publican sobre Fake News y manipulación periodística. Así también se tomaron en cuenta autores clásicos para precisar conceptos. El resto de las fuentes sitúan las referencias en 2018, cuando ya se están produciendo algunos avances para frenar las malas praxis periodísticas, sobre todo en los países donde se ha celebrado una contienda electoral.

\title{
Antecedentes
}

Si el futuro del periodismo dependiera en la actualidad de los usuarios, lectores, consumidores de contenidos, aquellos que antes pagaban un precio por el ejemplar, no está claro que fuera a sobrevivir. Durante varios siglos los medios 
de comunicación fueron un referente informativo, apuntalaron la sociedad democrática y se convirtieron en un poderoso negocio. El tránsito del siglo XX al XXI ha supuesto el principio del fin, aunque hay quien piensa que no es el final, sino la transición, la adaptación necesaria para ser atractivos nuevamente. Otra forma de crear información, de ofrecerla y de servirla. Ofertas "Premium" que diferenciarán el bueno del mal periodismo.

El inmovilismo le dio ventaja a la prensa impresa a través de los tiempos. No había que competir. La información fluía con naturalidad; eso sí, con cierta prisa. Pero la sociedad, que nunca está quieta $-\mathrm{y}$ menos la de ahora-, demandó otra forma de consumir la información que los medios tradicionales no podían ofrecer. El mundo digital llegó convencido de que, como había sucedido con otras revoluciones, la suya terminaría por asentarse. En cuanto la tecnología se hace más fácil de usar y descienden los costes, su avance es imparable. Los medios de comunicación ya no son un negocio de soñadores. Ahora, el paso lo marca la innovación; algo que le cuesta aplicar, aunque algunos esfuerzos están dando frutos, pues el cierre de ediciones ha permitido sobrevivir al menos a un medio impreso en algunas ciudades. Excepto en Pittsburgh:

Una de las grandes ciudades de los EE. UU. sin un periódico impreso diario, después de que el diario Post-Gazette informara a los lectores que recortará su programación de producción de siete días a la semana a cinco a partir de este fin de semana. Post-Gazette, que se lanzó hace 232 años, es uno de los periódicos más antiguos del país, había señalado en junio que el recorte finalmente sucedería en breve, al tiempo que señaló que la edición digital del periódico continuará. (Concha, 2018)

¿Qué hicieron los medios de comunicación cuando vieron asomar la tecnología en sus redacciones? ¿Cómo activaron sus mecanismos de defensa? ¿Implementaron herramientas para adaptarse al cambio? ¿Qué recursos económicos necesitaron para seguir ofreciendo el producto a primera hora de la mañana, en el caso de los periódicos? No hay una respuesta unificada a estas cuestiones. Los periódicos nunca han estado alejados de la tecnología. Todo el siglo XX fueron aplicando los inventos que llegaban de otras industrias como 
las máquinas rotativas, la mejora en el papel y el uso de tintas que secaban más rápido.

Luego, la velocidad a la hora de componer, editar y producir la información utilizó herramientas que permitían a los editores sacar la información cada 24 horas, o menos en el caso de diarios de la tarde. Entonces, si siempre han estado próximos a la tecnología, cómo es que en el siglo XXI han perdido esa proximidad. Al comienzo, las propias redacciones elaboraban contenidos idénticos para los medios impresos y digitales; luego, se separaron las redacciones para crear contenidos diferenciados y, por fin, hubo un regreso a los inicios creando una redacción centralizada para uno o varios productos, puesto que ya la información se facilita también a través de correo y sobre todo en las apps del propio periódico.

En el camino de esta revolución llegaron las redes sociales, cuando ni siquiera estaban establecidas las ediciones digitales de los medios de comunicación. Estos fueron introduciendo contenidos, luego informaciones, después comentarios y, por fin, algo parecido a las "News", lo cual permitía a sus seguidores estar informados. Ese fue el principio del fin. Ni siquiera los enlaces que ofrecían para ampliar la información han bastado para mejorar la llegada de nuevos lectores. Tampoco que Zuckerberg dijera que Facebook no era un medio de comunicación, que Twitter apoyaba a los medios y que el resto de las redes que existen y que vendrán dejarán de crear información.

En el fondo: medios, redes, empresarios, lectores, etc., siguen buscando una solución que restablezca el equilibrio. Y hay que trabajar con humildad, como señala David Skok al citar a Richard Gringas:

Creo que tenemos que ser más humildes. Como suelo decir, la tecnología tiene valor, pero no tiene valores. Es importante, cuando uno mira el ecosistema en busca de noticias, para entender y deconstruir lo que sucedió con el modelo anterior, y hacia dónde debemos avanzar, que pensemos antes ¿qué pasó? (Skok, 2018; traducción propia) 
La palabra clave junto con deconstruir sería repensar de nuevo el periodismo en todas sus facetas. La aplicación y los resultados vendrían luego. No experimentar por experimentar, como hacen muchos medios digitales. Pruebo esta sección, hago este tipo de informaciones con videos cortos o permito más comentarios en abierto para obtener ¿qué resultados?

\section{Objetivos}

Si bien la parte tecnológica es la clave de la transición de los medios de comunicación, especialmente en la etapa inicial - finales del siglo XX y principios del XXI-, lo cierto es que un nuevo panorama mediático está buscando hueco entre los consumidores. Todo ha sucedido muy deprisa, pero ahora comienzan a verse algunos resultados. La clave: 2016 y las elecciones a la presidencia de Estados Unidos. El apoyo recibido desde los medios digitales y sobre todo "fuerzas ajenas" desde Internet decantaron la balanza hacia el lado de los Republicanos. Luego vino el Brexit y también los resultados en el Proceso de Paz en Colombia. Y esto nos debería llevar a pensar que los medios ya no son tan decisivos en los procesos políticos, ni en la influencia de la sociedad, ni en el devenir de la historia. Lo son cada vez más las redes sociales y el control de Internet. Es, por tanto, el objetivo principal conocer y situar los medios en 2018 frente a las mentiras y falsedades de la información.

Tomemos como punto de partida la llamada "edad de oro" del periodismo, enfoque desde el cual Jeidi Tworek y John Maxwell Hamilton (2018) hacen una llamada de atención a los problemas por los que atraviesa el periodismo y por no haber sabido aprovechar los buenos momentos. Así las cosas, a principios de 1990 trabajaban en el negocio de las noticias unas 445.000 personas. A comienzos de 2017, este número se había reducido en un 50\%; es decir, unos 173.900 empleados en Estados Unidos. En España, el asunto era muy parecido y preocupante. Según publica El País, la crisis ha provocado el cierre de 375 medios de comunicación y desde 2008 más de 12.000 periodistas han perdido su puesto de trabajo. Estos datos, que provienen del Informe Anual de la Profesión Periodística elaborado por la Asociación de la Prensa de Madrid (APM) dirigida 
por Luis Palacio, vienen a señalar que la información ya no se elabora con un seguimiento preciso y constante, que los fondos documentales de esos medios de comunicación también están en peligro (Gómez, 2015).

No obstante esas cifras, el periodismo está vivo. Más vivo que nunca. Esta aseveración está justificada por los nuevos lectores digitales que, apoyados o no en las redes sociales, se han acercado a los periódicos digitales para ampliar la información. El goteo con que los medios impresos perdían lectores, se ha compensado de alguna manera con estos nuevos lectores llegados desde lo digital. No hay que olvidar tampoco que una parte de estos lectores tienen como cabecera un medio nacido completamente digital.

El pulso que sostienen los medios de comunicación frente a las redes sociales no se aguanta. El equilibrio ya está roto, pero la presencia de noticias que no se ajustan a la realidad, que se pueden manipular porque la técnica lo permite - también su rastreo hasta descubrir la fuente, en ocasiones - ha dado un vuelco a la manera en que se debe tratar la información. En especial, tras el descubrimiento de los datos facilitados por un exempleado de Cambridge Analytica que los utilizó para diseñar estrategias en campañas políticas con el fin de beneficiar a un determinado candidato. A partir de ese momento, como fichas de dominó fueron cayendo otros procesos electorales en los que se vigiló muy de cerca el uso de los datos para frenar informaciones falsas o tendenciosas.

Desde las elecciones de 2016 en EE. UU., todos los gobiernos han estado vigilantes en su proceso político para evitar posibles manipulaciones. Y, en concreto, los medios de comunicación han sido testigos de contenidos que no se ajustaban a la realidad. Hay que poner un freno a la impunidad con la que los medios se ven invadidos por bots que publican sin control para que luego los periodistas tomen como referencia datos falsos que conducen a situaciones periodísticas erróneas. Incluso cuando se abusa de las fuentes anónimas se está haciendo un flaco favor a los contenidos de los medios, porque supone que a veces las propias fuentes te han mentido y ahí aparece la responsabilidad del periodista para controlar y separar lo cierto de lo posible. 
De nada sirve que las fuentes anónimas se escuden en el resultado final de la información. No en tiempos de confusión, de engaño y de ocultación de la verdad. Dice Dan Gillmor que es mejor prescindir de determinadas fuentes, no volver a tomarlas, que dejarse guiar hacia un camino que no tiene regreso. Y avisa muy en serio a los periodistas:

No estoy sugiriendo que ningún periodista viole ninguna promesa que haya hecho en el pasado. Un trato es un trato, incluso si hemos sido engañados. Espero que algunos periodistas cambien los términos tradicionales en el futuro, tanto para su propia protección como para la del público. (Gillmor, 2015; traducción propia)

Se precisa, pues, un compromiso mayor con el actual sistema político, tan convulso en los tiempos actuales.

Estos antecedentes, tan recientes que nos acercan y a la vez nos alejan de propuestas concretas para crear informaciones verídicas, bien fundamentadas, organizadas y servidas a un público que recupere la credibilidad en los medios, terminarán por devolver al estado natural la información que se había descafeinado. Como en un movimiento cíclico, la ola está de regreso con nuevos planteamientos para empresas periodísticas y para redactores. El mundo de la información volverá a sus orígenes para ganar la batalla a los contenidos procesados por las máquinas, o por los intereses partidistas de algunos candidatos que quieren ganar elecciones desde el engaño y la mentira. Mientras tanto, la batalla está sobre el tablero. Las noticias son el sustento de una democracia que se ha visto amenazada, pero que lejos de rendirse ha establecido pautas para mejorar la vida de los ciudadanos.

Y las raíces que se están plantando ahora deben ser recias, fuertes y profundas, para que de esta crisis del periodismo, la profesión salga reforzada para el futuro. Porque como dicen algunos autores, no todos los medios sobrevivirán, pero los que queden seguirán teniendo un compromiso con la sociedad, el gobierno democrático y los usuarios a los que seguirán informando:

La gente siempre se ha preocupado por las noticias. Acaban de encontrar diferentes modos para reunirlas y consumirlas. Las próximas décadas se parecerán más a los tiempos anteriores a la 
edad de oro, cuando los periódicos compitieron con muchos otros métodos para reunir noticias. Esto no quiere decir que los periódicos estadounidenses no sobrevivirán. Algunos lo harán. Pero no tendrán la misma dominación que a mediados del siglo XX. Coexistirán con otros modelos. (Tworek y Maxwell, 2018; traducción propia).

El periodismo, como le sucede hoy al arte, la cultura y la literatura, se reinventará una vez más para asegurar la apuesta de la sociedad civil por la democracia.

\section{Formato de credibilidad + confianza}

El gran desafío que persiguen los políticos es la credibilidad. También los medios. Son tantas las maneras de acceder a la información que los usuarios digitales se dejan seducir por un canto de sirenas en la lejanía, pero se pierden cuando escuchan mensajes difusos que no son creíbles. Lo que hasta ahora venía siendo en la profesión periodística una necesidad para que el redactor ajustara su información a la realidad noticiosa, lo que le valdría el apoyo de ser creíble, ha pasado a mejor vida. Un lector digital puede leer y dar credibilidad a una noticia cuando el medio y el redactor se han ganado ese nivel. La posibilidad de leer un mismo hecho noticioso en varios lugares y comprobar que hay alguno que no se ajusta a la realidad, lleva al usuario digital a centrarse solo en determinados medios.

¿Se puede medir la credibilidad en formatos digitales? ¿Se está haciendo? ¿Qué medios influyen más en los políticos? ¿Qué valor dan a esos medios? Las cuestiones no tienen por qué plantearse como procesos definitivos, pero se ha venido midiendo la credibilidad de los medios, sobre todo en temas políticos. Precisamente, Reuters Institute presentó los datos de su Digital News Report 2018 sobre temas de confianza y desinformación, que son los que sustentan la credibilidad en los medios. Y aunque se pudiera pensar que en estos tiempos los resultados son malos, no lo son tanto, ya que el nivel medio de confianza en las noticias en general se mantiene estable en el 44\%. Mientras que en la mayoría de los países ha bajado, especialmente en Estados Unidos (-9), Dinamarca (-5) y Holanda ( -3$)$; en España ha crecido un punto $(+1)$ en relación con el estudio de 2017 (Reuters Institute, 2018). 
La pérdida de la credibilidad lleva a los lectores a estar preocupados por la información que reciben y para separar lo verdadero de lo falso, donde no siempre tienen herramientas para lograrlo. Así:

Más de la mitad (54\%) está de acuerdo o muy de acuerdo en que están preocupados por lo que es real y falso en Internet. Esto es más alto en países como Brasil (85\%), España (69\%) y los Estados Unidos (64\%), donde las situaciones políticas polarizadas se combinan con un alto uso de los medios sociales. El nivel más bajo se registra en Alemania (37\%) y los Países Bajos (30\%), donde las recientes elecciones no se vieron afectadas en gran medida por la preocupación por los contenidos falsos. (Reuters Institute, 2018, p. 9; traducción propia)

En el centro de este proceso, los medios de comunicación están cada día más vigilantes en cuanto a la forma en que los gobiernos intervienen en los procesos de información, especialmente en aquellas cadenas de televisión y radio, también el resto de los medios que son de titularidad pública. Todo con el fin de hacer frente a esta lacra de la desinformación.

Precisamente, la proximidad que existía antes entre los políticos y los periodistas se ha roto. Ya no es tan necesario como en el pasado tener cerca un periodista para comunicar a miles de usuarios la propuesta que el candidato quería realizar. Hoy, el político puede usar sus redes sociales, con miles de seguidores, amigos, visitantes, etc., para hacer llegar un mensaje sin la acción directa de un periodista. Entonces, para un político, ¿cuál es el medio de mayor confianza? Esta es la misma pregunta que Burson, Cohn y Wolfe se hizo, junto con ComRe: "What influences the influencers", con el fin de saber qué medios de comunicación eran más influyentes entre los líderes políticos en Europa. Resultó ser Político con un $69 \%$ el de más valor, seguido de Financial Times (62\%), la BBC (59\%) y The Economist (57\%) (véase figura 1). 
Figura 1. Medios más influyentes para los políticos de la Unión Europea

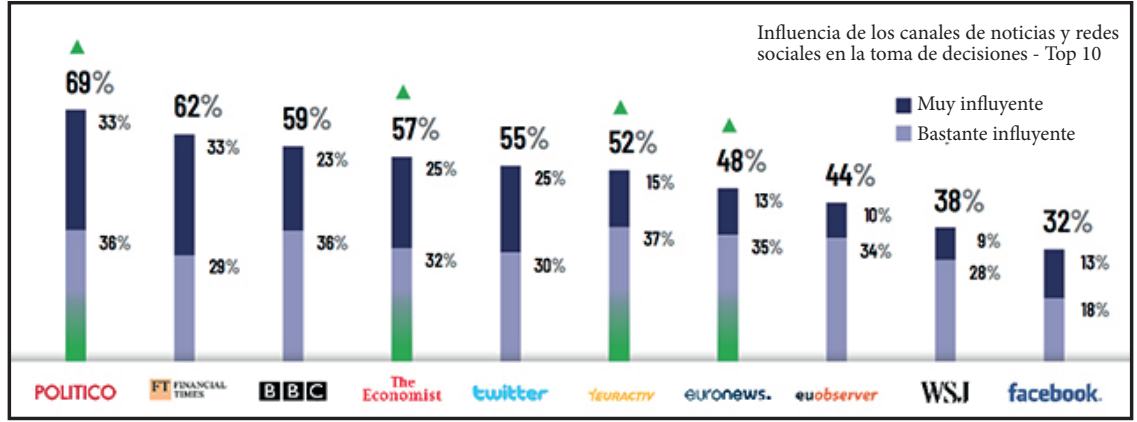

Fuente: Burson Cohn y Wolfe, 2018.

Con respecto a las redes sociales, los políticos prefieren Twitter (55\%) seguido de Facebook (32\%), LinkedIn (26\%) y YouTube (25\%). Estos datos referidos a Europa, señalan que las fuentes personales siguen creciendo en valor para los políticos, siendo WhatsApp, la herramienta en quien confían más para su intercambio de información profesional, seguida de Twitter (véase figura 2). Pasa a un tercer lugar Facebook, sobre todo a partir de la crisis de Cambridge Analytica.

Figura 2. Redes sociales más influyentes para los políticos de la Unión Europea

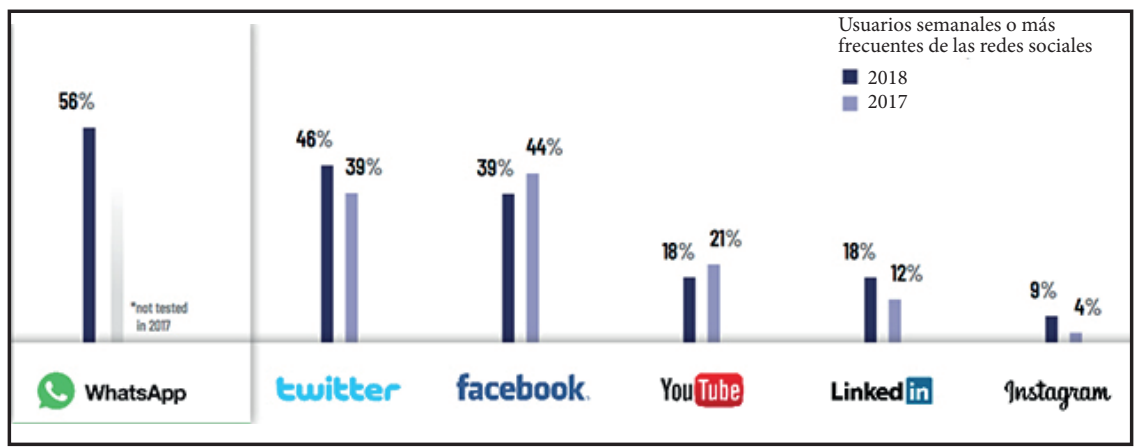

Fuente: Burson Cohn y Wolfe, 2018.

Por último, en España - y tomando como referencia el informe en español del Center for Internet Studies and Digital Life, de la facultad de Comunicación de la Universidad de Navarra, sobre la base de los datos obtenidos-, se indica que 
el $77 \%$ de los españoles considera que la información periodística se manipula para servir a intereses políticos o económicos (Amoedo, Vara y Negredo, 2018). Otros datos significativos aportados por dicho estudio explican que el $46 \%$ se ha encontrado ya alguna noticia manipulada en la última semana y, lo que es peor,

[d]os de cada tres internautas españoles consideran que los políticos abusan de la expresión "Fake News" para desacreditar a los medios que les desagradan, el mayor porcentaje de todos los países encuestados, y uno de cada tres españoles afirma haber visto este comportamiento en la última semana. (Amoedo, Vara y Negredo, 2018)

Así pues, la credibilidad sumada a la confianza es en estos tiempos la mejor manera para hacer un periodismo sin ataduras. Conscientes del reto de informar a una sociedad cada vez más dispersa, los periodistas tienen que conjurarse para dar mayor credibilidad a sus fuentes y ofrecer periodismo de calidad. Solo así serán capaces de fidelizar a sus lectores. Los políticos no han contribuido a que los medios sigan siendo un referente informativo, a no perturbar el orden y solo ofrecer informaciones a determinados periódicos o redes sociales, como está sucediendo en la actualidad en Estados Unidos.

\section{Periodismo de calidad}

La historia del periodismo ha constatado, a lo largo de más de doscientos años, la importancia que tienen las fuentes de información para llegar a entregar un producto de alta calidad. Calidad, en esta profesión, es ofrecer datos que otros medios no tienen; es construir la noticia con aportes personales, institucionaleslocales y proveyendo los elementos que dan valor a lo que se cuenta; es reunir todas las propuestas que implican lo acontecido y estructurarlas de tal modo que cuando el lector las lea sea capaz de entender la situación por la que ha pasado el periodista para contar esa historia.

En ningún caso hay que menospreciar el olfato periodístico, la inquietud y la duda ante cualquier información, la manera en que de soslayo y de frente se sitúa el periodista en una noticia, la estrategia que rompe los moldes para narrar situaciones que acontecen cada día, pero que hay que darlas a conocer como si fueran novedosas. Con todos los datos del hecho se puede empezar a producir el 
contenido, a redactar lo que se ha vivido como periodista, a posicionarse frente a una realidad, a escribir con la frialdad necesaria para contar lo que ha acontecido. Pues bien, si además contamos con otros datos que nos llegan desde el centro de documentación, se puede inferir que la noticia final es más completa, veraz y objetiva que cuando no se dispone de apoyos documentales.

Porque el periodismo se autoalimenta cada día, se inventa desde los tiempos iniciales en los que no importaba tanto el contenido como llegar a informar antes que tu rival. La palabra rivalidad y competencia, presentes en la historia del periodismo, se están devaluando cada vez más. Así, mientras van cerrando algunos medios en ciudades grandes de Estados Unidos, otros centros urbanos se ven obligados a fusionar dos medios y dejarlos en uno y, lo que es peor, todo va en detrimento de la calidad. Cuantos menos redactores y documentalistas hay en el medio, menos posibilidades y tiempo para elaborar bien los contenidos. Así se ha pasado de la calidad informativa que alcanzaron los periódicos en general en el siglo XX, a los tiempos actuales donde ya no hay revisores de textos ni editores gráficos ni nadie que supervise los contenidos; todo ello se traduce en conflictos del medio con la sociedad y rechazo por parte de los lectores.

Lo que el gran maestro del periodismo Edwin Emery llamaba "carrera en pos de la noticia", se ha quedado en un simulacro de emergencia. Todo interesa y todo se comunica a la máxima velocidad, pero ¿con el rigor preciso? Estamos reflexionando lo que publicamos o pasamos a la acción sin tiempo de espera. Al final, será cuestión de adaptarse, como Emery ya recordaba en el siglo XX: "Los editores de periódicos que habían tenido éxito aprendieron a adaptarse y adaptar sus periódicos a la nueva era. Casi todos ellos obraban por intuición" (1966, p. 241). Y, en la mayoría de edad del siglo actual, los medios de comunicación siguen buscando su adaptación al mundo digital, inconscientes de que dejan atrás un legado de información que carece de la calidad suficiente como para pasar a los anales de la historia. Lo que se produce ahora es solo información y datos con muy poca repercusión para el futuro.

Otro clásico del periodismo español, el profesor José Luis Martínez Albertos, señala lo que en origen fueron los mensajes a las audiencias: "En el comienzo de la revolución electrónica, buena parte de los individuos que 
integran los públicos de estos mensajes debía concentrase alrededor de unos pocos aparatos receptores que podían transmitirlos" (1997, p. 167). Ahora que los mensajes son digitales, que los públicos están tan dispersos que reciben multitud de informaciones, muchas idénticas y sin clasificar y que están experimentando cambios significativos, existe gran oferta para reproducir la información. Así pues, los cambios no son solo en la parte de la tecnología, sino en cómo se construye el mensaje ante las distintas audiencias: usuarios digitales tan dispersos, tan alejados de un punto central que antes solo respondían al nombre de un medio de comunicación.

Por último, se puede constatar que existe un periodismo confiable de alta calidad, en palabras de Tworek y Maxwell, cuando se rompen las barreras del miedo, de las falsas informaciones y de los cuestionamientos políticos, de forma constante, hacia algunos periodistas que están tratando de ofrecer contenidos que no gustan demasiado a los gobernantes. Pero la razón fundamental del periodismo es esa: no aceptar las presiones de políticos o de empresas que tratan de modificar la realidad para que parezca otra cosa. Más temprano que tarde se llegará a la calidad en la información, como ya existió hace dos décadas:

Es imperativo preservar el periodismo confiable de alta calidad en este momento cuando cualquier hecho inconveniente es etiquetado como "noticias falsas". Hoy el mismo concepto de verdad está siendo atacado y las empresas de prensa están en peligro por las instituciones políticas. (Tworek y Maxwell, 2018; traducción propia)

\section{Frente a la desinformación: buenas fuentes y herramientas de verificación}

Los medios de comunicación nunca antes se habían enfrentado a tantas situaciones al mismo tiempo. Y todas complejas. La llegada de las tecnologías rompió un equilibrio que se venía aprovechando por décadas. Y pilló desprevenidos a los editores. Mientras que las cuestiones técnicas mejoraban, los datos de venta de ejemplares o tiempo de permanencia en la televisión o escuchando la radio, iban cayendo. Además, tras los acontecimientos de 2016 ya descritos — triunfo de Trump, Brexit y Proceso de Paz en Colombia, entre otros-, los medios se vieron invadidos por muchas informaciones que no se ajustaban a la realidad. No eran comunicados de prensa de los partidos, ni empresas que querían "colar" una información cuando era un producto, ni instituciones o particulares que ofrecían 
sus actividades de manera generosa. El mundo se vio invadido por máquinas que movían millones de informaciones hasta crear un cambio en las personas, tanto en lo político como en lo social, etc. Y algunos periódicos contribuyeron a difundir esas mentiras.

No pasó mucho tiempo antes de que reaccionaran. Se dieron cuenta de que estaban siendo utilizados, manipulados y convertidos en espejo de intereses ocultos. Para frenar esas mentiras, algunos medios han realizado propuestas efectivas, que se emplean sobre todo en tiempos previos a las elecciones. No hay que olvidar que los comicios se siguen ganando en los medios tradicionales (periódicos, radio y TV), sumado ahora los digitales (redes sociales). En el caso de Estados Unidos, en 2016 Donald Trump invirtió ya más en digital que su rival, y consiguió la victoria.

No es objeto de este texto descifrar el nivel de Fake News que se siguen produciendo, sí es introducirnos en la sociedad de la posverdad a través de instituciones y organismos que cada día se enfrentan y hacen una evaluación de lo que publican los medios y lo califican como verdadero o falso. De esta manera, los usuarios digitales empiezan a distinguir quién dice la verdad y quién la oculta. Si sumamos el uso de buenas fuentes con el control de la tecnología, se llegará a mejorar la información.

Tomamos como punto de partida el trabajo que Gleen Kessler publicó en The Washington Post tras la Conferencia de Verificación de Datos, celebrada en Roma, sobre los movimientos de verificación de hechos. Esta conferencia, avalada por la International Fact-Checking Netwok (IFCN), presentó 149 datos de comprobación de hechos en 53 países, lo que viene a indicar, que si las Fake News son un problema, también existen ya organismos que están buscando soluciones. Aunque, como señala Mantzarlis, director de la IFCN, hay que pasar del experimento a la acción:

Los inspectores de hechos ya no son el movimiento de reforma periodística de nuevo rostro impulsado por las expectativas positivas. Somos árbitros arrugados de una guerra sin prisioneros para el futuro de Internet. Y nos comportamos como en los primeros días en que éramos un experimento. (En Kessler, 2018; traducción propia) 
Esta preocupación ha llegado a los propios medios que, para evitar la desinformación, emplean este tipo de herramientas. Por ejemplo, PolitiFact utilizó hasta 54 reclamos tras un trabajo de varios periodistas y editores en tres estados de EE. UU:. En Francia, el periódico Liberation apostó por emplear la marca del producto CheckNews.fr para resolver las consultas lanzadas por los lectores. Pero ¿qué es CheckNews y cuál es su compromiso? En realidad es un equipo de ocho periodistas que ya ha dado respuesta a más de 1600 preguntas de las 8000 que han recibido.

En Inglaterra, Full Fact es la herramienta que verifica las transcripciones de la BBC y del Parlamento y las somete a una base de datos para comprobar si son verdaderas. En Argentina, Chequeabot hace las mismas funciones escaneando automáticamente lo que publican más de 30 medios de comunicación; en Brasil, esa función la hace Aos Fatos. Por último, en Estados Unidos, el Duke Reporters Lab proporciona a PolitiFact, FatCheck.org y The Washington Post Fact Checker una lista de declaraciones para comprobar los hechos que se incluyen. La propia Universidad de Duke ha creado FactStream, una aplicación para extraer verificaciones.

No solo los medios de comunicación se han preocupado por verificar sus informaciones, también empresas tecnológicas están tratando de ayudar en la credibilidad de las noticias. A modo de ejemplo, Bitpress

[...] es el primer protocolo de confianza descentralizado que rastrea la credibilidad de las noticias al permitir que los periodistas y las organizaciones de noticias identifiquen los malos actores y la información errónea. Construido sobre una cadena de bloques, este proceso es completamente transparente, inviolable e inmune a la censura por parte de cualquier gobierno u organización. (Armbrust, 2018; traducción propia)

Lo cierto es que, en las últimas elecciones francesas, se puso en marcha un proyecto de periodismo colaborativo para buscar las Fake News. Mas de 100 periodistas en 33 redacciones diferentes hicieron un seguimiento a rumores, reclamos, imágenes y vídeos fabricados y los datos obtenidos se publicaron en CrossCheck, otro lugar de verificación. Por último, todas, las grandes 
redes sociales se han visto obligadas a dar este paso, sobre todo cuando Mark Zuckerberg se enfrentó a una comisión del Congreso de Estados Unidos y luego a un interrogatorio con legisladores europeos para borrar las noticias falsas y evitar en el futuro el mal uso de los datos.

\section{Resultados y discusión}

Si bien el siglo XXI entra en su mayoría de edad tecnológica y personal, la situación a la que se enfrentan los medios de comunicación es incierta. Lo es porque con las herramientas que se emplean en la construcción de la información no pueden luchar contra la desinformación total. Los ro-bots son poderosos reproductores de mentiras a escala nacional o local, especialmente en tiempos de elecciones. Como todos los robots son manipulados por el ser humano, entran en competición con las informaciones publicadas en los medios de carácter político para sembrar dudas en los usuarios.

La credibilidad de la información cuesta años conseguirla. Un medio tarda entre una media de 25 a 30 años en llegar a una gran parte de la población. Perderla es mucho más sencillo y rápido. Y, lo que es peor, ya no vuelven a conquistar a esos lectores/usuarios que abandonan el medio. Más aún cuando en la actualidad hay tantas ofertas informativas que permiten al lector que se siente engañado optar por otras publicaciones.

Lo que ganaron los medios de comunicación por derecho propio en más de doscientos años de historia, las redes sociales y algún gobierno con intereses de desestabilización lo han logrado en apenas unos meses. Hay que crear sistemas de información, bases de datos y buenas fuentes que mejoren los contenidos para restaurar la confianza en los medios. Para ello, al menos se requieren los siguientes elementos: a) un compromiso formal por parte de los Estados para frenar la avalancha de contenidos falsos y perseguir a las empresas que los faciliten; b) una puesta en común por parte de los medios, como ha sucedido con CrossCheck, para buscar soluciones integradas en muchas redacciones; c) dar a conocer a través de sitios web a los medios que incumplan los protocolos que defienden estos organismos e instituciones, para que el usuario identifique quién 
cumple y quién se deja arrastrar por la desinformación; d) una reflexión desde los propios medios, especialmente desde los responsables de la edición, para no presionar a los redactores a la hora de presentar los contenidos; e) en atención a la anterior propuesta, mejorar las herramientas de la redacción, apoyar con técnicos y especialistas en este tipo de herramientas y no mermar el número de redactores porque les obliga a estar en varios frentes y a no poder comprobar las informaciones antes de publicarlas (ese descenso de periodistas que se propone en las líneas iniciales de este texto se ha aprovechado por los "enemigos" de la información para introducir las malas informaciones sin tener mucha capacidad de respuesta); y f) hacer partícipes, como se demuestra en algunas de las herramientas propuestas, a los usuarios/lectores para que denuncien los sitios que publican informaciones falsas o cuando tengan dudas envíen textos a las redacciones y se puedan comprobar.

Es cierto que las noticias falsas siempre han existido. Los manuales de historia están plagados de ellas. Pero se han incrustado de tal manera que se pone remedio ahora o se tardarán muchos años en quitar esa lacra. Los esfuerzos son importantes, a tenor de lo propuesto en las líneas anteriores, mas se requiere una mayor implicación de las autoridades y de los propios medios. El periodismo es y será incómodo por naturaleza, no debe dejarse intimidar, ha de ser veraz y crítico con cada información y cuando se le requiera deberá interpretar los hechos. De esta forma, estará dando un servicio a la sociedad y cumpliendo con el mandato superior de informar en libertad para construir una democracia o aquel sistema de gobierno justo que se establezca entre los ciudadanos.

Al final de esta situación grave que atraviesan los medios de comunicación se saldrá adelante, con algunos heridos y varios muertos que ya están enterrados en las hemerotecas; así, para combatir las noticias falsas y hacer información de calidad se deben usar fuentes de información fiables y creíbles, preparadas por documentalistas que estén al servicio del propio medio, no de terceros intereses. Esto es lo que han venido haciendo los centros de documentación por muchos años: comprobar, verificar y apuntalar los datos que el periodista necesitaba. Todo ello se resume en una palabra clave: investigación. De tal forma lo atestigua la 
que fuera presidenta de la Federación de Asociaciones de Periodistas de España, Elsa González:

El periodista lo es siempre, y que cuando se mueve en las redes también lo es. El periodista es quien verifica la noticia. Un periodista tiene que ser absolutamente profesional, es decir, investigar, confirmar y no publicar ninguna información que no esté debidamente contrastada. Ahora mismo eso parece fácil pero teniendo en cuenta la velocidad que nos piden, la instantaneidad, el sensacionalismo que también se ha impregnado mucho más en los medios de comunicación. (En APM, 2018)

El final del proceso llegará, sobre todo, cuando se implique al usuario/ lector en el compromiso que tiene con la información. Serán ellos, junto con los periodistas, los que han de denunciar y no apoyar, los sitios que de forma reiterada sigan ofreciendo informaciones falsas o aprovechándose de los datos sin permiso de aquellos. Facebook sería el ejemplo, ya que tras Cambridge Analytica sufrió un descenso en su actividad.

\section{Conclusiones}

Es posible que necesitemos un nuevo modelo para el periodismo tecnológico, pero no lo es menos que parte de la solución está en manos de los medios de comunicación y de los propios periodistas. El manejo de sus fuentes ha de ser cada vez más necesario y a la vez estricto. No todo vale, sigue siendo un lema aceptado en la profesión. No todo tan rápido, debería ser el lema de estos tiempos tan acelerados. Comprobar la información, contrastarla con otras fuentes, solicitar al centro de documentación apoyos para verificar los datos debe llevar a presentar una información más seria, rigurosa, veraz y objetiva. En definitiva, a crear contenidos informativos de calidad.

Está claro que son tiempos de desajuste en el periodismo. Que la sociedad es cada día más plural, multicultural y colaborativa, que el mundo se mueve hacia otros destinos y que frente a tanta información en la punta de los dedos, la que de verdad tiene valor es aquella que puede aportar una nueva visión de los medios. Es posible que sobren contenidos, que la actualidad del día se sepa mirando la pantalla del móvil y que lo que de verdad ayude a crear una conciencia social sea la lectura pausada de los medios, algo que se está perdiendo. Los periódicos 
y las revistas impresas serán las que nos ofrezcan esa manera de entender la información, fruto de la reflexión.

Para llegar a una información de calidad, los periodistas han de cambiar los tiempos de actuación. Llegar el primero no garantiza una mejor información como en tiempos de la imprenta. Lo que da valor a un medio es la información crítica. Por tanto, la primera consideración es que el periodista utilice su pensamiento de manera crítica. Luego, la mala información, los datos erróneos, etc., deben evitarse contando con apoyos del propio medio a través del centro de documentación. En último lugar, verificar cada envío que se recibe de empresas, partidos políticos, organismos, ONG, etc. Y, especialmente, lo que llega desde Internet y las redes sociales.

No hay que olvidarse de los intentos de manipulación orquestados por especialistas en estas técnicas, sobre todo aquellos que tratan de confundir y/o manipular cada vez que se ofrece información. El periodista entró en un mundo de desinformación acelerada, pero como otras modas que han existido, esta también pasará.

\section{Referencias bibliográficas}

Amoedo, A.; Vara, A.; Negredo, S. (2018). Una audiencia diversa y preocupada por la desinformación. DigitalNewsReport.es. Center for Internet Studies and Digital Life, Facultad de Comunicación, Universidad de Navarra. Recuperado de http://www.digitalnewsreport.es.

APM (24 de abril de 2018). El periodismo de calidad es el antídoto contra las 'Fake News'. Asociación de Periodistas de Madrid. Recuperado de https://bit.ly/2HZnLE8.

Armbrust, L. (16 de mayo de 2018). Bitpress: An Open Protocol for Tracking the Credibility Of News [Bitpress: un protocolo abierto para rastrear la credibilidad de las noticias]. Bitpress. Recuperado de https://bit. ly/2ZM9yD4.

Burson Cohn y Wolfe. (2018). 2018 EU Media Survey: What influences the influencers. $B C W$. Recuperado de: https://bit.ly/2Mvv33s.

Concha, J. (27 de agosto de 2018). Pittsburgh becomes largest US city without a 
daily print newspaper [Pittsburgh se convierte en la ciudad más grande de los Estados Unidos sin un periódico impreso diario]. The Hill. Recuperado de https://bit.ly/2PECQyQ.

Emery, E. (1966). El periodismo en Estado Unidos. Ciudad de México: Trillas.

Gillmor, D. (19 de diciembre de 2015,). News organizations: If your sources lie to you, out them [Organizaciones de noticias: si tus fuentes te mienten, fuera de ellas]. Medium. Recuperado de https://bit.ly/2DDNocp.

Gómez, R. (16 de diciembre de 2015) La crisis ha provocado el cierre de 375 medios de comunicación. El País. Recuperado de https://bit.ly/2EyrlGY

Kessler, G. (25 de junio de 2018,). Rapidly expanding fact-checking movement faces growing pains [El movimiento de verificación de hechos que se expande rápidamente se enfrenta a situaciones de crecimiento]. The Washington Post. Recuperado de https://bit.ly/2GVTB5T.

Martínez Albertos, J. L. (1997). El mensaje informativo. Barcelona: ATE.

Posetti, J., Matthews, A. (2018). A Short Guide to the History of 'Fake News' and Disinformation: A Learning Module for Journalists and Journalism Educators. s. 1.: International Center for Journalist. Recuperado de https://bit.ly/2JTttXe.

Skok, D. (10 de mayo de 2018). Google's news chief Richard Gingras: "We need to rethink journalism at every dimension [El jefe de noticias de Google, Richard Gingras: "Necesitamos repensar el periodismo en cada dimensión"]. Niemanlab. Recuperado de https://bit.ly/2J3oHd4.

Reuter Institute (2 de abril de 2018). Digital News Report 2018. Reino Unido: Reuter. Recuperado de https://bit.ly/2JDOTwv.

Tworek, H. y Hamilton, J. M. (2 de mayo de 2018). Why the "golden age" of newspapers was the exception, not the rule [¿Por qué la "edad de oro" de los periódicos fue la excepción, no la regla?]. Niemanlab. Recuperado de https://bit.ly/2V2eh4w. 